\title{
Access to the 340B Drug Pricing Program: is there evidence of strategic hospital behavior?
}

\author{
Karen Mulligan ${ }^{1 *}$, John A. Romley ${ }^{1,2}$ and Rebecca Myerson ${ }^{3}$
}

\begin{abstract}
Objective: The 340B Drug Pricing Program allows hospitals to purchase covered drugs at a discount and potentially generate profit if they are reimbursed at rates that exceed 340B acquisition prices. Disproportionate share hospitals (DSH) are eligible to participate in 340B if their DSH adjustment-a measure that identifies hospitals that treat a disproportionate share of low income Medicare or Medicaid patients-is above $11.75 \%$. To assess whether hospitals behave strategically to gain access to the program, we examined data on the number of hospitals just above versus below the DSH adjustment threshold for 340B eligibility and conducted McCrary density tests to assess statistical significance.

Results: In 2014-2016, the number of hospitals increases by 41\% just above the 340B eligibility threshold. McCrary density tests found this increase to be statistically significant across a range of bandwidths in 2014-2016 ( $p<0.01)$. From 2011-2013, the findings are sensitive to the bandwidth around the threshold, but insignificant in 2008-2010. We found no comparable change among hospitals ineligible for the 340B program. These data are consistent with the hypothesis that some hospitals adjust their DSH to gain 340B eligibility. Our findings support recent calls from the Government Accountability Office to improve oversight of the 340B program.
\end{abstract}

Keywords: 340B, Hospitals, Strategic behavior, Policy

\section{Introduction}

The 340B Drug Pricing Program was established in 1992 to enable covered entities, including hospitals, to stretch scarce federal resources by allowing them to purchase covered drugs at an estimated $20-50 \%$ discount [1]. Hospitals owned by state or local government or nonprofit hospitals with a contract with state or local government to provide healthcare services to low-income individuals who are not entitled to benefits under Medicare or Medicaid are eligible to participate in 340B [2, 3]. In addition to meeting this requirement, disproportionate share (DSH) hospitals must treat a "disproportionate" number of Medicaid patients. Specifically, to qualify for 340B,

\footnotetext{
*Correspondence: karenmul@usc.edu

1 Sol Price School of Public Policy and Leonard D. Schaeffer Center for Health Policy \& Economics, University of Southern California, 635 Downey Way, VPD Hall, Los Angeles, CA 90089, USA

Full list of author information is available at the end of the article
}

these hospitals must have a DSH adjustment percentage above $11.75 \%$ [4].

As noted by the US Government Accountability Office (GAO), hospitals can generate profit from 340B program participation by purchasing covered drugs at the discounted price for all patients and receiving reimbursement from insured patients that may exceed the $340 \mathrm{~B}$ prices paid $[5,6]$. Estimated per hospital profits from participating in 340B were $\$ 2.5$ million in 2016, which accounts for a relatively small share of overall operating budgets [7]. Prior data suggest that US health care stakeholders adapt their behavior to incentives generated by the policy environment [8-11]. This study assessed the plausibility of strategic behavior to gain access to the $340 \mathrm{~B}$ program by comparing the distribution of hospital DSH near the eligibility cutoff to what would be expected by chance alone, in the absence of strategic behavior.

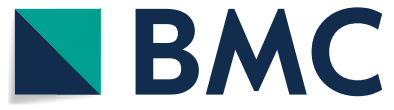

(c) The Author(s) 2021. This article is licensed under a Creative Commons Attribution 4.0 International License, which permits use, sharing, adaptation, distribution and reproduction in any medium or format, as long as you give appropriate credit to the original author(s) and the source, provide a link to the Creative Commons licence, and indicate if changes were made. The images or other third party material in this article are included in the article's Creative Commons licence, unless indicated otherwise in a credit line to the material. If material is not included in the article's Creative Commons licence and your intended use is not permitted by statutory regulation or exceeds the permitted use, you will need to obtain permission directly from the copyright holder. To view a copy of this licence, visit http://creativeco mmons.org/licenses/by/4.0/. The Creative Commons Public Domain Dedication waiver (http://creativecommons.org/publicdomain/ zero/1.0/) applies to the data made available in this article, unless otherwise stated in a credit line to the data. 


\section{Main Text Methods}

Our sample included US non-profit and public acute care hospitals with non-missing DSH information in the Healthcare Cost Report Information System (HCRIS) for at least 1 year between 2008 and 2016 [12]. We excluded critical access hospitals, which do not have a DSH requirement for $340 \mathrm{~B}$ participation, as well as sole community hospitals and rural referral centers, which face a lower DSH requirement (8\%) for 340B eligibility [13]. Because our study focused on general acute care hospitals, we also excluded children's hospitals and freestanding cancer hospitals, which comprise less than $3 \%$ of all 340B hospitals [14]. Investor-owned (i.e. "for-profit") hospitals are ineligible irrespective of DSH and were excluded from the main analysis.

Small hospitals must report a capped value of $12 \%$ DSH even if their actual DSH is higher [15]. In our sample, $40.7 \%$ of hospital-year observations $(\mathrm{N}=11,361)$ were subject to the DSH cap. We therefore calculated "true" DSH for all hospitals using formulas published by the Centers for Medicare \& Medicaid Services [15]. Among uncapped hospitals in our sample, reported and calculated DSH had correlation of +0.996 .

We grouped hospitals by true DSH into 1 percentage point bins, with no bins containing $11.75 \%$, and graphed the number of hospitals in each bin just above and below the $11.75 \%$ eligibility threshold. If hospitals are adjusting their DSH to gain eligibility, we expect this graph to show a sharp increase in the number of hospitals just above $11.75 \%$. We also used McCrary density tests with true DSH as the running variable to assess whether the observed difference in density of hospitals just below and above the $11.75 \%$ threshold was significantly larger than what would be expected by chance alone [16]. Thus, our analysis focuses on bunching in the hospital DSH distribution just above the $340 \mathrm{~B}$ eligibility threshold at a given point in time.

We conducted several alternate specifications to assess the robustness of findings. First, we repeated the McCrary density test using bandwidths (ranges of data near the cutoff) equal to 1, 3, 5 as well as a mean-standard-error optimal bandwidth calculated using a local polynomial estimator [17]. Because 340B eligibility is not affected by DSH values other than $11.75 \%$, a null hypothesis of no manipulation does not generate falsifiable predictions about the DSH density of hospitals far from the threshold. To test for comparable changes in the distribution of DSH at points other than the $11.75 \%$ threshold, we repeated the analysis using placebo DSH cutoffs ranging from $6.75 \%$ to $16.75 \%$. Third, we conducted a placebo analysis using data from investor-owned hospitals, which are ineligible for 340B irrespective of DSH. Finally, since DSH depends partly on Medicaid inpatient days, an increase in the number of hospitals above the threshold might simply reflect expansions of eligibility for Medicaid to low-income, non-disabled adults implemented in many states starting in 2014 under the Affordable Care Act (ACA). To examine whether this accounted for our findings, we repeated the analysis after dropping states that implemented Medicaid eligibility expansions.

\section{Results}

Figure 1 presents histograms of the DSH variable among public and non-profit hospitals, compared with investorowned hospitals, which were never eligible for 340B. In 2014-2016, the number of hospitals just above the threshold increases by $41 \%$ compared to the number just below it. Prior to 2014, this pattern was much less pronounced.

McCrary density tests found a significant increase just above the 340B eligibility threshold in 2014$2016(\mathrm{p}<0.01)$. This finding was present for all bandwidths examined. From 2011-2013, the statistical significance of the change at the threshold was sensitive to the bandwidth used; the change was statistically significant $(\mathrm{p}<0.01)$ for the optimal bandwidth $(4.0$ below the threshold and 4.3 above) as well as bandwidths of 2 and 5 , but not for the bandwidth equal to 1 . The McCrary density test did not identify significant changes in the number of hospitals at the 340B eligibility threshold prior to 2011.

Sensitivity checks suggested the robustness of findings. We found no comparable evidence of changes in the number of hospitals at cutoffs other than $11.75 \%$. There was no significant change in the number of hospitals at the $11.75 \%$ threshold for the investor-owned hospitals, a group of hospitals that is ineligible for the 340B program. Additionally, our findings were robust to dropping states that expanded Medicaid eligibility (Fig. 2). While this suggests Medicaid eligibility expansions do not explain the increase in hospitals just above the threshold in 2014-2016 for the full sample, we cannot rule out the possibility that Medicaid expansions impacted hospitals in non-expansion states that are located near the border of an expansion state.

\section{Discussion}

This paper documents an increase in the number of hospitals whose DSH is just above the $340 \mathrm{~B}$ eligibility cutoff. This increase at the cutoff is significantly larger than what would be expected by chance alone in 2014-2016; there is suggestive evidence of an increase in 2011-2013, and no evidence of an increase prior to 2011. These patterns 


\section{A. Non-profit and public hospitals near $340 \mathrm{~B}$ eligibility threshold}
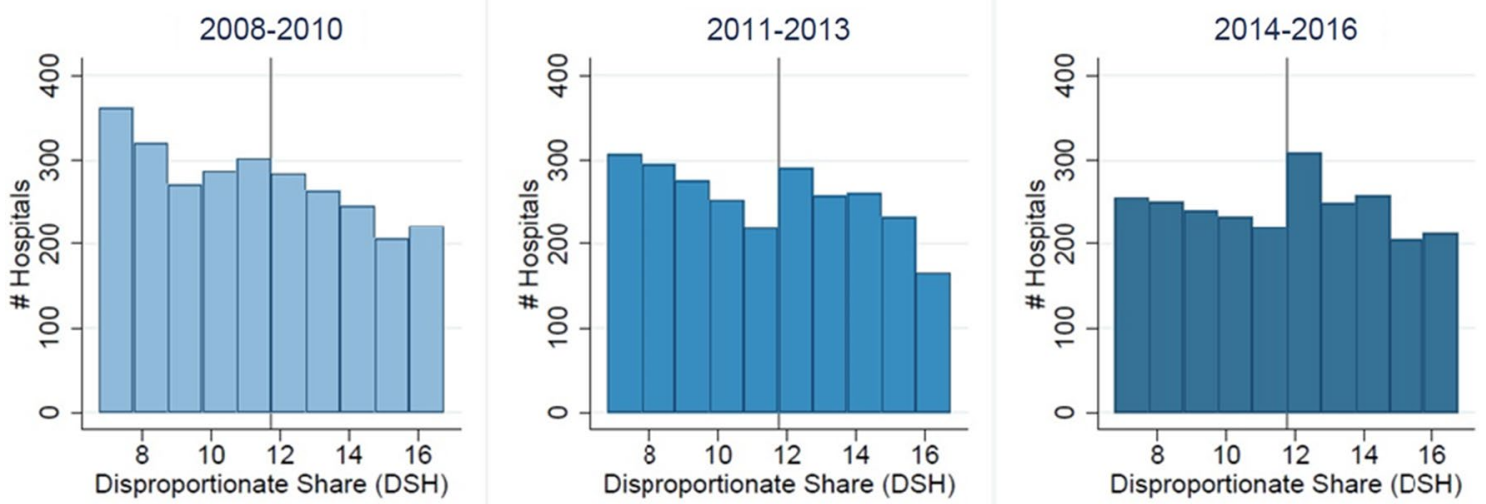

B. Investor-owned hospitals near $340 \mathrm{~B}$ eligibility threshold (placebo check)
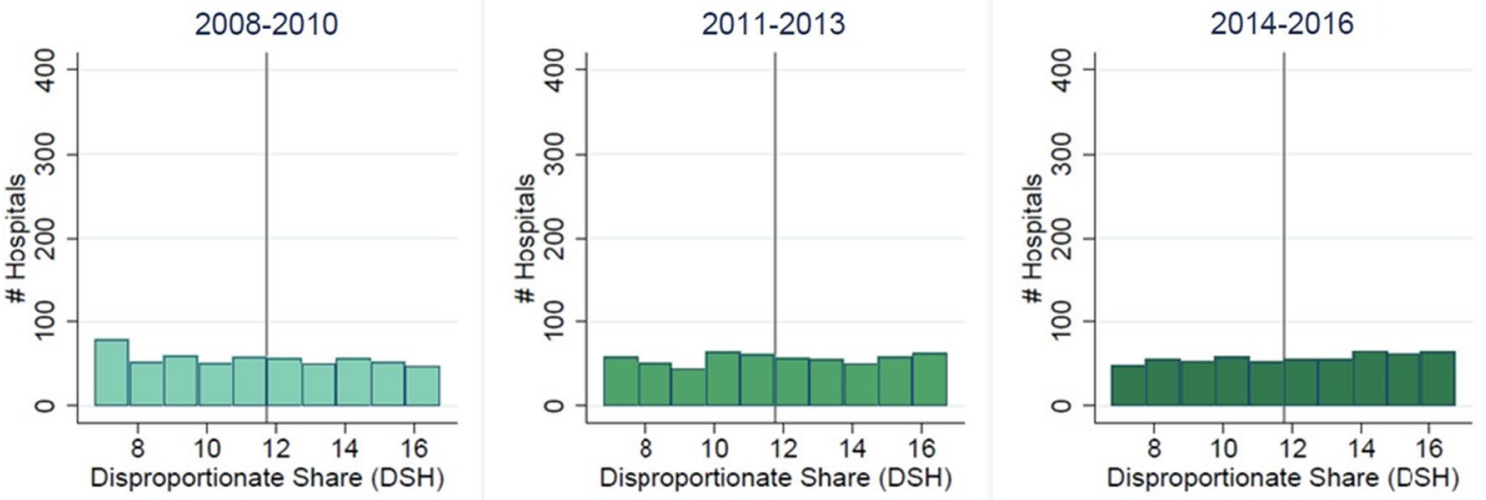

Fig. 1 Number of Hospitals near the 340B Eligibility Threshold. Vertical line indicates 340B eligibility threshold (DHS=11.75\%). Hospitals are grouped into 1 percentage-point bins, with no bin containing DSH $=11.75 \%$. Public and non-profit hospitals with DSH greater than $11.75 \%$ are eligible for 340B; investor-owned hospitals are not eligible for 340B irrespective of DSH

are consistent with a hypothesis that some hospitals adjusted their DSH to gain 340B eligibility, although this is a fairly recent phenomenon.

The possibility of DSH adjustment was examined in a previous study that used a regression discontinuity design (RDD) to estimate the effect of the 340B program on hospital-physician consolidation and the administration of non-oral drugs by hospital-owned facilities [18]. In particular, the RDD estimates would be invalid if hospitals strategically adjust the factors (i.e. DSH) that determine 340B program eligibility [19]. Desai and McWilliams (2018) used data from 2008-2012 [18], and our results for 2008-2010 are consistent with theirs. However, for 2011-2013 (i.e., 2 year overlap with the previous study), we found that the statistical significance of McCrary density tests was sensitive to bandwidth. Desai and McWilliams (2018) did not find evidence of manipulation, however they used graphical analysis and analyzed changes in the same hospital over time rather than McCrary density tests [18]. From a methodological standpoint, our results suggest that RDD may not be a valid approach for studying the 340B program, particularly after 2014 when we find the strongest statistical evidence consistent with strategic behavior.

Although we cannot determine the mechanism that drives our results, several possibilities exist. First, hospitals may have increased their DSH through better record keeping without substantive changes in patient mix. Better record keeping would be consistent with observed high adoption rates of electronic health records by hospitals following the passage of the ACA [20]. Alternatively, administrators at hospitals near the eligibility threshold may have accepted more Medicaid or dual eligible patients in order to move their DSH above the $11.75 \%$ cutoff. Finally, it is possible that some hospitals near the 


\section{A. Non-profit and public hospitals near $340 \mathrm{~B}$ eligibility threshold}
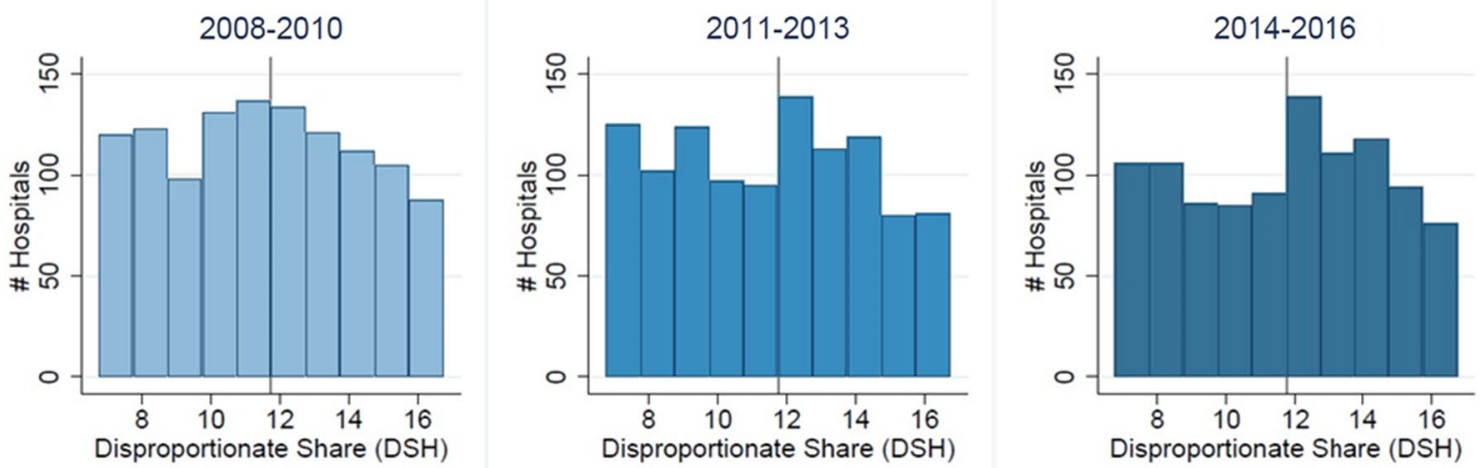

\section{B. Investor-owned hospitals near 340B eligibility threshold (placebo check)}
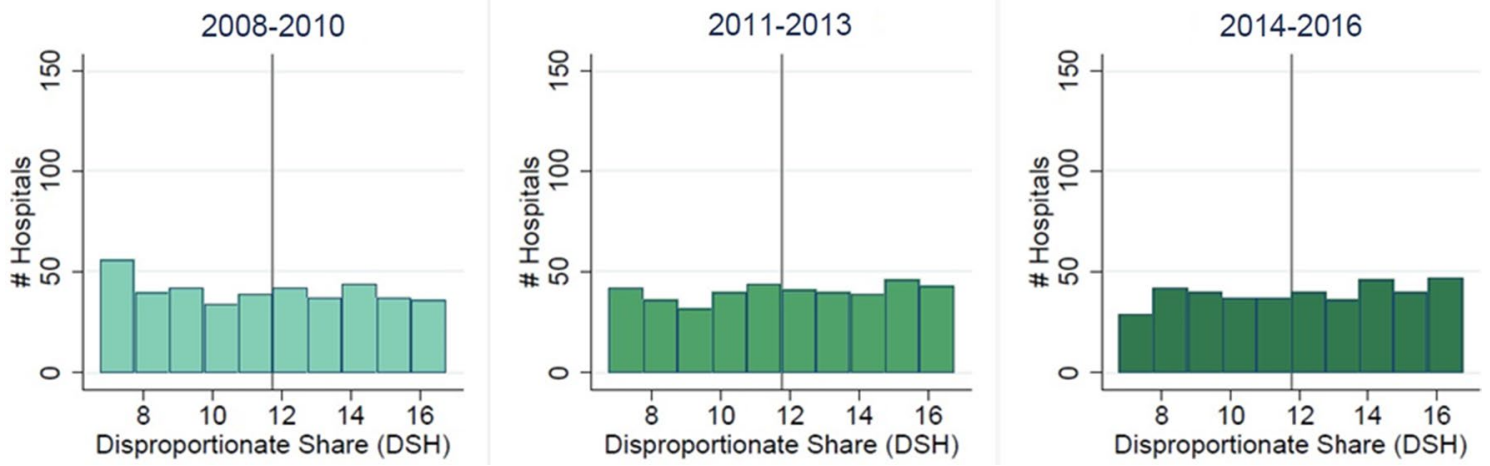

Fig. 2 Number of Hospitals Near the 340B Eligibility Threshold in States that did not Expand Medicaid. Vertical line indicates 340B eligibility threshold (DHS $=11.75 \%$ ). Sample includes hospitals in states that expanded Medicaid following the Affordable Care Act. Hospitals are grouped into 1 percentage-point bins, with no bin containing DSH =11.75\%. Public and non-profit hospitals with DSH greater than 11.75\% are eligible for 340B; investor-owned hospitals are not eligible for 340B irrespective of DSH

eligibility cutoff misreported their DSH or the underlying patient mix to gain access to the 340B program.

Our data are relevant to ongoing policy discussions. While there is some oversight of the $340 \mathrm{~B}$ program, it is limited, with only 200 covered entities receiving audits annually [21]. The GAO has issued calls for improved reporting and oversight in the $340 \mathrm{~B}$ program $[5,21]$. Our data support these calls for additional oversight and suggests attention could be focused on hospitals near the eligibility threshold.

\section{Limitations}

The primary limitation of our study is related to interpretability of results. Our findings of more hospitals above the threshold than would be expected by chance only applies to hospitals "near" the eligibility threshold. For example, in 2016 there were 2189 hospitals in our main sample, with 185 having true DSH 2 percentage points or less above the threshold. Thus, based on a back-of-the-envelope calculation, at most roughly $8 \%$ of hospitals may have adjusted their DSH to shift just above the $340 \mathrm{~B}$ eligibility threshold. While strategic behavior to adjust DSH may be more widespread (i.e., hospitals may adjust DSH well beyond the threshold), available statistical tests do not allow us to check for this possibility. Finally, while $340 \mathrm{~B}$ has been available since 1992, the costs and benefits tied to 340B participation by hospitals may have shifted over time. While this is an important issue, it is outside the scope of this paper and an area for future research.

\section{Abbreviations}

ACA: Affordable Care Act; DSH: Disproportionate share; GAO: Government Accountability Office; HCRIS: Healthcare Cost Report Information System.

\section{Acknowledgements}

The authors would like to thank Catherine Ishitani for research support and Karen Van Nuys for feedback. 


\section{Authors' contributions}

KM, RM, and JAR designed the study. KM collected and cleaned the data. KM and RM analyzed the data. KM, RM, and JAR drafted. All authors read and approved the final manuscript.

\section{Funding}

None.

\section{Availability of data and materials}

Please contact the corresponding author (Karen Mulligan) to request a copy of the data used for this research.

\section{Declarations}

\section{Ethics approval and consent to participate}

Not applicable.

\section{Consent for publication}

Not applicable.

\section{Competing interests}

The authors declare that they have no competing interests.

\section{Author details}

${ }^{1}$ Sol Price School of Public Policy and Leonard D. Schaeffer Center for Health Policy \& Economics, University of Southern California, 635 Downey Way, VPD Hall, Los Angeles, CA 90089, USA. ${ }^{2}$ School of Pharmacy, University of Southern California, Los Angeles, USA. ${ }^{3}$ Department of Population Health Sciences, University of Wisconsin-Madison, Madison, USA

Received: 15 January 2021 Accepted: 27 May 2021

Published online: 03 June 2021

\section{References}

1. US Government Accountability Office. Medicare Part B Drugs: Action Needed to Reduce Financial Incentives to Prescribe 340B Drugs at Participating Hospitals. 2015;GAO-15-442.

2. PHSA. $\$ 340(B)(a)(4)(L)(i)$

3. Limitation on prices of drugs purchased by covered entities. 42 U.S.C. $\S 256 b(4)(\mathrm{L})(\mathrm{i})$

4. Health Resources \& Services Administration. 340B Eligibility. 2018. https:// www.hrsa.gov/opa/eligibility-and-registration/index.html.

5. United States Government Accountability Office. 340B Drug Discount Program: Increased Oversight Needed to Ensure Nongovernmental Hospitals Meet Eligibility Requirements. 2019. Report No.: GAO-20-108.

6. United States Government Accountability Office. Manufacturer Discounts in 340B Program Offer Benefits, but Federal Oversight Needs Improvement. 2011. Report No.: GAO-11-836.
7. Conti RM, Nikpay SS, Buntin MB. Revenues and profits from medicare patients in hospitals participating in the 340B drug discount program, 2013-2016. JAMA Netw Open. 2019:2(10):e1914141.

8. Walker J, Weaver C. The $\$ 9$ Billion upcharge: how insurers kept extra cash from medicare. Wall Street J. 2019. https://www.wsj.com/articles/the-9billion-upcharge-how-insurers-kept-extra-cash-from-medicare-11546 617082.

9. Decarolis F. Medicare part D: are insurers gaming the low income subsidy design? Am Econ Rev. 2015;105(4):1547-80.

10. Brown J, Duggan M, Kuziemko I, Woolston W. How does risk selection respond to risk adjustment? New evidence from the medicare advantage program. Am Econ Rev. 2014;104(10):3335-64.

11. Starc A, Town RJ. Externalities and benefit design in health insurance. Rev Econ Stud. 2020:87(6):2827-58

12. Centers for Medicare and Medicaid Services. Healthcare Cost Report Information System (HCRIS). https://www.cms.gov/Research-StatisticsData-and-Systems/Downloadable-Public-Use-Files/Cost-Reports/.

13. Health Resources \& Services Administration. 340B Program Hospital Registration Instructions. 2019. https://www.hrsa.gov/sites/default/files/hrsa/ opa/hospital-registration-instruction-details.pdf. Accessed 28 Apr 2021

14. United States Government Accountability Office. Drug Discount Program: Characteristics of Hospitals Participating and Not Participating in the 340B Program. 2018 Jun. Report No.: GAO-18-521R.

15. Centers for Medicare and Medicaid Services. Medicare Disproportionate Share Hospital Fact Sheet. 2019. http://www.cms.gov/Outreach-andEducation/Medicare-Learning-Network-MLN/MLNProducts/Downloads/ Disproportionate Share Hospital.pdf.

16. McCrary J. Manipulation of the running variable in the regression discontinuity design: a density test. J Econ. 2008;142(2):698-714.

17. Imbens G, Kalyanaraman K. Optimal bandwidth choice for the regression discontinuity estimator. Rev Econ Stud. 2012;79(3):933-59.

18. Desai S, McWilliams JM. Consequences of the 340B Drug Pricing Program. N Engl J Med. 2018;378(6):539-48.

19. Lee DS, Lemieux T. Regression discontinuity designs in economics. J Econ Liter. 2010;48(2):281-355

20. Henry J, Pylypchuk Y, Searcy T, Patel V. Adoption of Electronic Health Record Systems among U.S. Non-Federal Acute Care Hospitals: 2008 2015. Washington, DC: Office of the National Coordinator for Health Information Technology; 2016. (ONC data brief). Report No.: 35

21. US Government Accountability Office. Federal Oversight of Compliance at 340B Contract Pharmacies Needs Improvement. 2018 Jun. Report No.: GAO-18-480

\section{Publisher's Note}

Springer Nature remains neutral with regard to jurisdictional claims in published maps and institutional affiliations.

Ready to submit your research? Choose BMC and benefit from:

- fast, convenient online submission

- thorough peer review by experienced researchers in your field

- rapid publication on acceptance

- support for research data, including large and complex data types

- gold Open Access which fosters wider collaboration and increased citations

- maximum visibility for your research: over 100M website views per year

At BMC, research is always in progress.

Learn more biomedcentral.com/submissions 